\title{
Resonance Frequencies Behavior in Pathologic Cries of Newborns
}

\author{
Yasmina Kheddache and Chakib Tadj \\ Department of Electrical Engineering, École de Technologie Supérieure, $\mathrm{H} 3 \mathrm{C}$ 1K3 Montréal (Qc), Canada
}

Corresponding Author:

Yasmina Kheddache,

e-mail: yasmina.kheddache.1@etsmtl.net

kheddache_y@hotmail.com

fax: + (001) 514 396-8684

\begin{abstract}
Objective: A new approach to the automatic quantification of the acoustic parameters of the cries of healthy newborns and newborns with pathologies is presented. The purpose of the present study was to examine the relationship between acoustic parameters and pathologies of interest to characterize healthy and pathologic cries of newborns. Methods: Using Matlab, this study included automatic estimation of F0, RF1, RF2, percentage and tuning duration, transition duration, RF2 slope, and RF1:RF2 ratio. The database used includes full-term and preterm newborns, healthy and pathologic cries. It contains 3000 cry samples of 1 s duration from 65 newborn babies aged from 1 day to 1 month old. Results: Statistical analysis results reveal that the distributions of these acoustic cry parameters depend on the pathology of newborn. In this work, we successfully identify the quantitative relationship between the acoustic cry characteristics we examined and the diseases we studied. Conclusion: Our deduction is that quantification of the variability of these parameters is useful for differentiating the cries of a healthy newborn from those of a newborn with a pathology, and that these data can be used for the early diagnosis of newborn diseases.
\end{abstract}

Keywords: Newborn cry; resonance frequencies; tuning, transition duration, RF2 slope, RF1:RF2 ratio 


\section{Abstract}

Objective: A new approach to the automatic quantification of the acoustic parameters of the cries of healthy newborns and newborns with pathologies is presented. The purpose of the present study was to examine the relationship between acoustic parameters and pathologies of interest to characterize healthy and pathologic cries of newborns. Methods: Using Matlab, this study included automatic estimation of F0, RF1, RF2, percentage and tuning duration, transition duration, RF2 slope, and RF1:RF2 ratio. The database used includes full-term and preterm newborns, healthy and pathologic cries. It contains 3000 cry samples of $1 \mathrm{~s}$ duration from 65 newborn babies aged from 1 day to 1 month old. Results: Statistical analysis results reveal that the distributions of these acoustic cry parameters depend on the pathology of newborn. In this work, we successfully identify the quantitative relationship between the acoustic cry characteristics we examined and the diseases we studied. Conclusion: Our deduction is that quantification of the variability of these parameters is useful for differentiating the cries of a healthy newborn from those of a newborn with a pathology, and that these data can be used for the early diagnosis of newborn diseases.

Keywords: Newborn cry; resonance frequencies; tuning, transition duration, RF2 slope, RF1:RF2 ratio.

\section{Introduction}

In this paper, the newborn cry is assessed acoustically, in order to correlate its acoustic properties to specific pathological conditions and to show how acoustic variations in the cry reflect the degree of distress of the newborn. In most crying research, the spectrogram has been used in cry analysis $[1,2,3]$. This method of analysis requires manual selection, which in turn requires some technical knowledge. In our work, we automate the evaluation of acoustic cry characteristics in order to improve infant monitoring in the first days of life.

To further investigate the relationship between infant crying and medical conditions from which infants may suffer, a set of the most important acoustic measures must be selected containing the most relevant information available based on physiological models of cry 
production. It is also important to understand the physioacoustic structure and levels of the nervous system responsible for muscle control and cry production.

The various acoustic characteristics are formed in accordance with changes in the status of the vocal tract, and may be affected by activity along the entire vocal production pathway, including respiration, vocal fold behavior, and vocal tract shape $[4,5]$.

Greater control of vocalization in infants at around 1 to 2 months of age leads to greater differentiation in their cries, as a result of the physiological and anatomical changes occurring during this period. According to [6], at around 3 months of age, crying is context-dependent, intentional, and communicative. At around 7 months, "babbling" occurs [7]. Consequently, because from 1 month of age, infants begin to acquire voluntary control of the vocal tracts [8], looking at the spontaneous cries of infants during the first weeks of life is crucial if we are to apply this information to the early diagnosis of various newborn pathologies. Our study concentrates on the characterization of the cries of newborns 1 day to 1 month old.

In this paper, the acoustic characteristics of healthy and pathological cries of preterm and fullterm newborns are measured by automated means. The median and interquartile range of these characteristics are used to assess the degree of variation of:

- the average resonance frequencies (RF1, $\mathrm{RF} 2)$ and the $\mathrm{RF} 1 \mathrm{RF} 2$ ratio;

- the fundamental frequency (F0);

- the percentage and duration of tuning periods (TUP) for RF1 and RF2 with the first 10 harmonics of F0;

- the duration of the transition periods (TRP) between two consecutive TUPs;

- the RF2 slope.

These acoustic parameters were selected based on previous studies in which their usefulness, either for the development of phonatory and articulatory capabilities or for characterizing the 
production deficit in dysarthric speech, was reported. In $[9,10,11]$, for example, the authors conclude that the irregular behavior of any of these parameters could provide suggest possible neurological dysfunction.

However, F0 and its variations over time are viewed as an essential component of reliable information on the health status of newborns $[12,13]$, and resonance frequencies (RFs) reflect important acoustical characteristics of the vocal tract of the infant [9]. Transition duration and tuning between RFs and the F0 harmonics have not been determined in infants younger than 4 months [10]. These characteristics are interpreted as early articulatory activity in the infant cry [14], and are related to the development of phonatory and articulatory capabilities [10].

The RF1:RF2 ratio is an important marker of the relationship between the first and second formants, and helps us to understand the resonance frequencies (RFs) behavior in healthy and pathological newborn cries. This parameter is used to evaluate changes in voice and articulation in children with cochlear implants, for example $[15,16]$.

Also, the RF2 slope has been reported in previous studies as one of the most sensitive indices of vocal tract function for speech production. It has been considered to be an indicator of the severity of dysarthria and of neurodegenerative diseases [11]. This parameter has not yet been measured in newborns or younger infants, however.

The method typically applied for RFs estimation is the parametric autoregressive approach. This method is particularly well suited to the assessment of the newborn cry, which is characterized by higher RFs than those of adults [9, 17]. For F0 estimation, we use the SIFT algorithm, described in $[12,13]$.

This paper is organized as follows. We first present a physioacoustic model of the newborn cry in section 2, and characteristics of newborns cries in a medical environment in section 3 . 
We then explain our methodology for measuring the characteristics of pathological and healthy cries in section 4 . In sections 5 and 6 , we provide a follow-up analysis of the results, and present our conclusions in section 7 .

\section{Physioacoustic Model and Neurological Basis of the Newborn Cry}

The cry signal is the result of coordination among several areas of the brain which control respiration and the vocal fold vibration from which the cry sounds are produced $[1,5]$. These sounds are created by the respiratory system (lungs and trachea), the vocal folds (larynx), and the vocal tract (pharynx, and oral and nasal cavities) [6].

Cry sounds are generated in the larynx, which contains the vocal folds and glottis, by air being forced through a constricted tube, which causes vibration of the vocal folds at F0. This sound is then filtered as it proceeds through the vocal tract and the lips. The vocal tract acts as a resonance cavity, and its instantaneous shape determines the RFs. So, the cry sound is affected by formant frequency, the size and contours of upper vocal tract resulting in the audible cry $[8,18]$.

The shape of the newborn's vocal tract is more like that of a chimpanzee than that of a human adult, where the position of the larynx is higher in the vocal tract. The vocal tract of the newborn is also shorter $(\mathrm{L} \approx 8.5 \mathrm{~cm})[18]$ and has a different structure than that of an adult. This means that it is associated with higher resonances and a higher fundamental frequency than it is in adults [19], because the formant frequencies decrease as the length of the resonance tract increases.

F0 varies from $250 \mathrm{~Hz}$ to $450 \mathrm{~Hz}$, with an initial formant at a frequency FR1 of $1100 \mathrm{~Hz}$ and a second formant at a frequency FR2 of $3100 \mathrm{~Hz}$ [1]. Vocal fold vibrations produce three identifiable modes of cry, defined as: a) a basic cry or phonation with F0 $=350-750 \mathrm{~Hz}$; b) a 
cry with a high F0 (750-1000 Hz) or hyperphonation F0 (1000-1800 Hz); and c) noisy, turbulent, or dysphonic cries $[12,13,20]$.

Interaction between laryngeal and pharyngeal activity is interpreted by tuning processes between the cry melody and the resonance frequencies [14]. The tuning period (TUP) is defined as the time $(>20 \mathrm{~ms})$ during which an $\mathrm{RF}$ remains close to the harmonic distance $(<100 \mathrm{~Hz})$. Transition duration $(\mathrm{TRP})$ is time between two consecutive TUPs $[9,18]$. TRP depends on neuro-physiological maturity and the integrity of the underlying control systems [10]. According to [21], RFs tuning at round F0 increases the sound level of the vocal output.

The nervous system innervates the muscles that control the respiratory system, the vocal folds, and the vocal tract [6]. Consequently, the characteristics of cries are influenced by the cranial nerves that innervate the larynx, pharynx, and chest $[6,8]$.

\section{Newborn Cry Characteristics in a Medical Environment}

Deficits in brain functioning can affect the vagal control of the cry [1]. Many of the early researchers examined healthy and pathological cries by observing spectrograms and the spectra of the audio signals of cries. They essentially assert that infant cries are dependent on physical and psychological status, as well as both internal and external stimuli $[5,18,22,23]$. In spite of differences in measurement procedures, all cry studies have shown that a high F0 is an indicator of a neurological problem [5]. Hyperphonic cries and very high pitched cries are associated with neurological problems [5]. Other markers associated with neonatal disease include noisy or dysphonic cries, as well as changes in phonation mode, and variability in F0 and F1 $[12,17,20]$. When a CNS (central nervous system) disorder is involved, the cry exhibits auditory abnormalities with a high F0 and an irregular melodic contour [8].

The work conducted in [12] shows that the average percentages of hyperphonic segments in 
cry samples are similar for both healthy premature infants and healthy full-term newborns. It also shows that the average percentages of F0 irregularity are slightly higher for premature infants than for healthy full-term newborns. In addition, according to [20], the average percentages of dysphonic segments in the cry samples of healthy preterm newborns are higher than those of healthy full-term newborns. This difference may be a result of the immature innervation of the larynx in preterm newborns.

RF1 and RF2 have been used to identify differences between children who are profoundly deaf and those with normal hearing. [15]. According to [5, 8], high variability in RF1 and RF2 (dysregulation) indicates poor or unstable neural control of vocal track and respiration. This characteristic has been associated with hyperbilirubinemia, as well as prenatal tobacco and cocaine exposure. A higher than normal RF1 has been considered to be representative of an excitable neurobehavioral syndrome resulting from the direct effects of cocaine [24].

\section{Method}

\subsection{Recording sessions}

The recordings were made in the Pediatrics department at Sainte-Justine Hospital under the supervision of medical personnel. The cries of newborns 1 day to 1 month old were recorded using a small recording device placed $10 \mathrm{~cm}$ from the baby's mouth, at a sampling rate of 44.1 kHz. These include full-term and preterm newborn cries (premature infants at under 37 weeks' gestation and full-term infants at 37 to 42 weeks' gestation), healthy infants, and infants suffering from pathological conditions.

The cries of each infant were recorded two or three times at intervals of at least one hour over a period of not more than ten days. The conditions during which the cries were recorded were: hunger, blood sampling, and diaper changing. The date and time of recording, and the infant's ID, birth date, diagnosis, ethnicity, and so on, were noted for each crying episode. In 
order to confirm the health status of the infant or to determine that an undiagnosed health problem was, in fact, present during recording, we noted the results of a follow-up examination conducted six months after the cries had been recorded. We further categorized the cry recordings by pathology and by gestational age. A sample from the newborn cry database (CDB) that we created is presented in Table 1 . The CDB contains 3000 cry samples of $1 \mathrm{~s}$ duration from 65 newborn babies.

\subsection{Procedure}

Noise filtering and segmentation of the recordings into useful and non useful categories were performed in the first step of the assessment procedure using Praat. For the acoustic analysis of newborn cries, an automated assessment procedure was performed using Matlab to measure the characteristics defined in Table 2. The main steps of the assessment procedure are presented in Figure 1.

We applied the following procedure for acoustic characteristic measurement:

- Division of the cry samples of $1 \mathrm{~s}$ in duration into overlapping frames of $\mathrm{N}=1024$ samples, resulting in 512 covered frames, and the multiplication of each frame by the Hamming window.

- For each data frame, the first five acoustic measures defined in Table 2 were estimated as follows:

- Estimation of F0 and its 10 harmonics using the SIFT algorithm (simple inverse filtering tracking) [25].

- Estimation of RF1, RF2 using the modified covariance method based on autoregressive power spectral density (AR-PSD) [18,19].

- Calculation of the $\mathrm{RF} 1: \mathrm{RF} 2$ ratio $\left(\mathrm{V}_{\text {ratio }}\right)$.

- Determination of the tuning between the RFs and the first 10 harmonics.

- For each cry sample of $1 \mathrm{~s}$ duration, we estimated: 
- the average $\mathrm{F} 0, \mathrm{RF} 1, \mathrm{RF} 2\left(\mathrm{~A}_{\mathrm{F} 0}, \mathrm{~A}_{\mathrm{RF} 1}, \mathrm{~A}_{\mathrm{RF} 2}\right)$;

- the average $\mathrm{RF1}: \mathrm{RF} 2$ ratio $\left(\mathrm{A}_{\text {ratio }}\right)$;

- the tuning percentage of $\left(\mathrm{P}_{\mathrm{TUP}}\right)$;

- the tuning duration ( $\left.\mathrm{D}_{\mathrm{TUP}}\right)$ for $\mathrm{RF} 1, \mathrm{RF} 2$ and its average $\left(\mathrm{A}_{\mathrm{TUP}}\right)$;

- the transition duration $\left(\mathrm{D}_{\mathrm{TRP}}\right)$ for RF1, RF2 and its average $\left(\mathrm{A}_{\mathrm{TRP}}\right)$;

- the extent of the transition;

- the RF2 slope $\left(V_{S L P}\right)$ and its average $\left(A_{S L P}\right)$. (absolute values were taken for the slope and the extent of the transition.

The following formulas were used:

$$
\begin{aligned}
& \mathrm{A}_{\mathrm{F} 0}=\frac{\sum \mathrm{F} 0}{\mathrm{~N}_{\text {Total }}}, \mathrm{A}_{\mathrm{RF} 1}=\frac{\sum \mathrm{RF} 1}{\mathrm{~N}_{\text {Total }}}, \mathrm{A}_{\mathrm{RF} 2}=\frac{\sum \mathrm{RF} 2}{\mathrm{~N}_{\text {Total }}}, \mathrm{A}_{\text {ratio }}=\frac{\sum \mathrm{V}_{\text {ratio }}}{\mathrm{N}_{\text {Total }}}, \\
& \mathrm{P}_{\mathrm{TUP}}=\frac{\mathrm{N}_{\text {TUP }}}{\mathrm{N}_{\text {Total }}}, \mathrm{A}_{\mathrm{TUP}}=\frac{\sum \mathrm{D}_{\mathrm{TUP}}}{\mathrm{N}_{\mathrm{TUP}}}, \mathrm{A}_{\mathrm{TRP}}=\frac{\sum \mathrm{D}_{\mathrm{TRP}}}{\mathrm{N}_{\mathrm{TRP}}}, \mathrm{A}_{\mathrm{SLP}}=\frac{\sum \mathrm{V}_{\mathrm{SLP}}}{\mathrm{N}_{\mathrm{TRP}}}
\end{aligned}
$$

$\mathrm{N}_{\text {Total }}$ : Total number of segments in cry samples of $1 \mathrm{~s}$ duration.

$\mathrm{N}_{\text {TUP }}$ : Number of frames where tuning occurred between RF1, RF2 and the F0 harmonics. $\mathrm{N}_{\text {TRP }}$ : Number of transition durations in cry samples of $1 \mathrm{~s}$ duration.

- Calculation of the median and interquartile range of the evaluated characteristics of pathological cries and healthy cries.

\subsection{Resonance frequencies estimation}

The cry signal as a speech signal contains both vocal tract and pitch information. In this paper, we use the source filter linear model of speech production in which the glottis and the vocal tract are considered independently. So, passing the glottal pulse train through the filter makes it possible to remove the correlation between the vocal tract information and the pitch information [26]. 
Assuming that the vocal tract acts as the filter, then, according to the all-pole autoregressive (AR) model, the cry signal is the output of an all-pole filter $1 / A(\mathrm{z}), A(\mathrm{z})$ being called the inverse filter.

Consequently, the cry sample is a weighted linear combination of $\mathrm{n}$ previous samples described by the equation:

$$
y(k)=\sum_{i=1}^{n} a_{i} y(k-i)+w(k)
$$

where: $\mathrm{N}$ is the number of samples in a frame; $\mathrm{k}=[1 \ldots . \mathrm{N}] ; y(k)$ is the cry signal.

$w(k)$ is the prediction error or (LP) residual, which contains the excitation contribution to the cry signal; $a_{i}$ are the $A(z)$ polynomial coefficients; and $n$ is the model order.

However, the formant structures of the model are defined by the zero of the filter $A(\mathrm{z})$, which corresponds to the power spectral density peaks of the cry signal.

The filter equation is:

$$
A(z)=1+\sum_{i=1}^{n} a_{i} z^{-i}
$$

The power spectral density is given by:

$$
P S D(f)=\frac{1}{\left|1+\sum_{i=1}^{n} a_{i} e^{-2 j p f T}\right|^{2}}
$$

The RFs are therefore obtained by peak picking in the autoregressive power spectral density (AR-PSD), which is estimated using the modified covariance method. This method reduces spectral line splitting and the bias of frequency estimation [27]. It is based on simultaneously minimizing the forward and backward prediction errors $\mathrm{w}(\mathrm{k})$ in the least squares sense.

The model order $\mathrm{n}$ is chosen by means of the following formula: $\mathrm{n}=\sim 0.5 \mathrm{Fs}(\mathrm{kHz})$. For Fs $=$ 44.1 $\mathrm{kHz}, \mathrm{n}=22$. This relation comes from the physical constraint $\mathrm{n}=2 \mathrm{LFs} / \mathrm{c}$, where $\mathrm{L}$ is the 
length of the vocal tract $=8.5 \mathrm{~cm}$, and $\mathrm{c}=34 \mathrm{~cm} / \mathrm{ms}$, which is the speed of sound [18]. Formant splitting may occur if $\mathrm{n}$ is overestimated, while an underestimation of $\mathrm{n}$ smoothes the spectrum and causes the misallocation of spectral peaks [18].

\subsection{Fundamental frequency estimation}

In this paper, the modified SIFT algorithm is used to determine F0. It was demonstrated that this algorithm includes the autocorrelation properties and the ceptral pitch analysis technique [17]. In addition, the performance of this algorithm has been tested on the database of real newborn cries $[18,27]$.

This method is based on determining the autocorrelation sequence after performing glottal inverse filtering to attenuate the influence of the vocal tract.

The coefficients $\left\{\mathrm{a}_{\mathrm{i}}\right\} \mathrm{i}=[1, . ., 4]$ of the inverse filter $A(\mathrm{z})$ are determined by a forward linear predictor which minimizes the prediction error in the least squares sense [25].

Knowing $\left\{\mathrm{a}_{\mathrm{i}}\right\}$, the inverse filter output $\left\{\mathrm{s}_{\mathrm{k}}\right\}$ can be calculated using the equation:

$$
s_{k}=y_{k}+\sum_{i=1}^{4} a_{k} y_{k-i}
$$

Then, the output autocorrelation $\left\{r_{i}\right\}$ sequence is calculated as the autocorrelation sequence of $\left\{s_{k}\right\}$.

$$
r_{j}=\sum_{k=0}^{N-1-j} s_{k} s_{k+j}, \mathrm{j}=[1, . ., N-1]
$$

Then, peak picking is performed and a decision algorithm in which the peak value is compared to the voice threshold is applied $[14,25]$. F0 is estimated using the following equation:

$$
T 0=1 / F 0=\arg \max \left\{r_{j}\right\}
$$

The contour of the F0 result is then smoothed by the median filter. 


\section{Results and Analysis}

Plots of typical examples of the estimated F0 and its harmonics with resonance frequencies RF1, RF2 superimposed are presented on a color scale in Figure 2. This figure shows that and early harmonics-resonance interaction exists in both the healthy and pathological cries of newborns. Figures 2(a) and 2(b) show that healthy cries contain relatively long periods of adjusted RF1 tuning with a fast transition duration time. In Figure 2(c), RF1 is low with a long tuning period. Figure 2(d) shows low RF1, RF2 with fast tuning and long transition duration for RF1 and unstable transition duration for RF2. Figure 2(e) shows high RF1, RF2 with long transition duration and relatively fast tuning for RF2. In Figure 2(f), F0 is more irregular and the RFs are moving to the nearest harmonic to form a tuning event. Sudden pitch changes are noted in Figures 2(d) and (f), which cause changes in the harmonic and RFs structures.

The various results of our investigation into the distribution of the acoustic characteristics of healthy and pathological cries that we studied are presented by pathology and by gestational age using a box-and-whiskers plot $\left(25^{\text {th }}, 50^{\text {th }}\right.$, and $75^{\text {th }}$ percentile $)$ in Figures 3 and 4 . The recordings used for this assessment are those of premature newborn cries (p) and those of full-term newborn cries ( $\mathrm{t}$ ), and include healthy infants and infants suffering from the pathologies listed in Table 2 .

\subsection{F0, RF1, and RF2 estimation results}

Table 3 shows the median and interquartile range of the average F0, RF1, RF2 for all the pathologies studied. According to these results and those shown in Figure 3(a), the median and interquartile range of the average F0 in the case of Asphyxia (t), Vena cava thrombosis (t), and IUGR-microcephaly (P) are higher than those of healthy full-term newborns. The median and interquartile range of the average F0 for healthy preterm newborns is lower than that of healthy full-term newborns. This difference may be attributable to the difference in 
age at recording. The smallest inter-quartile range of the average F0 is found in the Tetralogy of Fallot $(\mathrm{P})$ and the largest inter-quartile range of the average $\mathrm{F} 0$ is found in Lingual frenum (t) following Asphyxia (t).

As for the estimated RF1 average, its highest median and interquartile range are found in Lingual frenum (t), as shown in Figure 3(b) and Table 3. In cases of IUGR_asphyxia (P) and the Tetralogy of Fallot $(\mathrm{P})$, the estimated median is high compared to those of healthy fullterm and preterm newborns. But the interquartile range of the average RF1 in the case of the Tetralogy of Fallot (P) is the smallest. The lowest medians for the estimated RF1 average are found in Meningitis ( $\mathrm{t}$ ) and Peritonitis ( $\mathrm{t}$ ).

The estimation results in Table 3 and Figure 3(c) on the average RF2 indicate that the median of the average RF2 for IUGR_asphyxia (P) is higher and the interquartile range larger than those of the other pathologies studied or of healthy newborns. We also found that the median is high and the interquartile range large for Lingual frenum $(t)$, and that the median of the average RF1, RF2 in healthy full-term newborns is lower and the interquartile range smaller than those of healthy preterm newborns. The lower medians are evident in both Vena cava thrombosis ( $\mathrm{t}$ ) and Peritonitis ( $\mathrm{t})$.

\subsection{RF1:RF2 ratio and RF2 slope evaluation results}

The medians and interquartile ranges of the $A_{\text {ratio }}$ are shown in Table 3 and Figure 3(d). The results indicate a median value that is relatively the same for both healthy full-term and preterm infants and also for newborns suffering from IUGR-microcephaly $(\mathrm{P})$ and RDS (P), but with different interquartile ranges. The highest median, $\mathrm{A}_{\text {ratio }}$, is associated with the cries of newborns with Lingual frenum(t), and the lowest with those with Vena cava thrombosis (t). As for Asphyxia (t), IUGR_asphyxia(P), the Tetralogy of Fallot (P), and Gastroschisis P, the $A_{\text {ratio }}$ cry signal medians are higher than those in healthy cry signals, and for Meningitis (t) and Peritonitis $(t)$ they are lower. The $A_{S L P}$ median and interquartile range results for the 
for both healthy and pathological newborn cries are given in Table 3 and illustrated in Figure 3(e). These results indicate that the median of $\mathrm{A}_{\mathrm{SLP}}$ in healthy full-term newborns cries is slightly higher than in those of healthy preterm newborns. The newborn cries of infants with IUGR-microcephaly $(\mathrm{P})$ or Vena cava thrombosis $(\mathrm{t})$ are characterized by a high $\mathrm{A}_{\mathrm{SLP}}$ median and a large interquartile range, unlike the newborn cries of newborns with Lingual frenum(t), which are characterized by a smaller $A_{S L P}$ median compared with either healthy or pathological newborn cries. Also, not surprisingly, the $\mathrm{A}_{\text {slp }}$ median is lower than those of healthy newborns for Asphyxia (t), Meningitis (t), RDS (P), IUGR_asphyxia(P), the Tetralogy of Fallot (P), and Gastroschisis P).

\subsection{TUP and TRP evaluation results for RF1 and RF2}

The various TUP and TRP measurements of the RFs are shown in Table 4 and Figure 4. The results shown in Figures 4(a), 4(b), and 4(c) indicate that the median and interquartile range of $\mathrm{P}_{\mathrm{TUP}}$ between RF1 and the harmonics of F0 are relatively the same in healthy full-term and preterm newborns, and $A_{\text {TRP }}$ is the same in both cases. But the $A_{\text {TUP }}$ median is the highest in the healthy preterm cries studied. The $\mathrm{P}_{\text {TUP }}$ median between RF1 and the F0 harmonics is the highest in Lingual frenum(t), Meningitis (t), Gastroschisis $(\mathrm{P})$, the Tetralogy of Fallot $(\mathrm{P})$, and IUGR-microcephaly $(\mathrm{P})$. The lowest $\mathrm{P}_{\mathrm{TUP}}$ medians are found in IUGR_asphyxia $(\mathrm{P})$ and in Vena cava thrombosis $(\mathrm{t})$, but with a large interquartile range. Higher $\mathrm{A}_{\text {TUP }}$ medians for RF1 in Lingual frenum (t), Meningitis ( $\mathrm{t})$, Peritonitis ( $\mathrm{t})$, Gastroschisis $(\mathrm{P})$, and RDS $(\mathrm{P})$ are noted compared with those of the other pathologies studied and those of healthy newborns. The lowest $\mathrm{A}_{\mathrm{TUP}}$ median and the highest $\mathrm{A}_{\mathrm{TRP}}$ median for RF1 with a large interquartile range are noted in Vena cava thrombosis $(\mathrm{t})$. The lowest $\mathrm{A}_{\mathrm{TRP}}$ medians for RF1 are found in Lingual frenum (t), Meningitis (t), IUGR_asphyxia (P), and the Tetralogy of Fallot (P).

As for $\mathrm{P}_{\mathrm{TUP}}, \mathrm{A}_{\mathrm{TUP}}$, and $\mathrm{A}_{\mathrm{TRP}}$ between RF2 and the F0 harmonics, Table 4 and Figures 4 (d), 4(e), and 4(f) indicate that the estimated median of $\mathrm{P}_{\mathrm{TUP}}$ and $\mathrm{A}_{\mathrm{TUP}}$ in healthy full-term 
newborns are higher than those of preterm newborns. Unlike $\mathrm{P}_{\mathrm{TUP}}$ and $\mathrm{A}_{\mathrm{TUP}}$, the $\mathrm{A}_{\mathrm{TRP}}$ median is the lowest in healthy full-term cries. We note the same lower $\mathrm{P}_{\text {TUP }}$ median in Lingual frenum ( $\mathrm{t})$, Vena cava thrombosis $(\mathrm{t})$, and RDS $(\mathrm{P})$. In Meningitis $(\mathrm{t})$ cries, we found a higher $\mathrm{P}_{\text {TUP }}$ median and a lower $\mathrm{A}_{\text {TRP. }}$ The highest $\mathrm{A}_{\text {TUP }}$ median is found in Peritonitis ( $\mathrm{t}$ ) cries, and the highest median and largest $\mathrm{A}_{\mathrm{TRP}}$ interquartile range are found in the cries of newborns suffering from Lingual frenum(t) and IUGR_asphyxia(P).

\section{Discussion}

An average value is greatly influenced by extreme values, which is not the case for a median. For this reason, we chose to represent our evaluation results in the form of medians and interquartile ranges in this work. This method of display is useful, because it makes possible both global and local dispersion of the data results.

In this study, we first focus our attention on the resonance frequencies (RF1, RF2), the RF1:RF2 ratio and the RF2 slope, which notify us of changes in the configuration of the vocal tract. To understand the behavior of F0 and (RF1, RF2) in healthy and pathological newborn cries, we concentrated our investigation on the percentage and duration of tuning ( $\left.\mathrm{P}_{\mathrm{TUP}}, \mathrm{A}_{\mathrm{TUP}}\right)$, as well as on the transition duration $\left(\mathrm{A}_{\mathrm{TRP}}\right)$ for both RF1 and RF2. These two acoustic phenomena can tell us whether or not a true relationship exists between F0 and the RFs at an early age in the newborn, and also whether or not the various medical conditions we studied influence the extent of these acoustic phenomena.

The association we have established between the characteristics of newborn cries and the pathologies studied is provided in Table 5. This association is based on our comparison of the cries of pathological and healthy newborns.

According to [16], in a normal group of children aged 3.8 to 10.2 years, $\mathrm{A}_{\text {ratio }}$ varies between 0.5 and 0.63 . In our study, we found a significant difference in this parameter between 
healthy newborns aged 1 day to 1 month and pathological newborns of the same age. This is presumably because successful word production requires greater and more rapid changes in vocal tract geometry than cries. In spite of the increase in RF1 and RF2 in healthy preterm newborn cries compared to healthy full-term newborn cries, we found no significant difference in either case for the estimated $\mathrm{A}_{\text {ratio. }}$ In the case of pathological cries, the values were higher than they were for healthy newborns for some pathologies and lower for others. However, lower values of $A_{\text {ratio }}$ are attributable to the decrease in RF1 values, and higher values of $A_{\text {ratio }}$ are the result of increased RF1 values. $A_{\text {ratio }}$ is related to the position of the tongue in the oral cavity. RF1 is associated with tongue height, and RF2 refers to tongue advancement [11]. These relationships are confirmed by the results of our study. Among the congenital malformations, Lingual frenum(t) cries are characterized by the highest RF1 and $\mathrm{A}_{\text {ratio }}$ of all the healthy and pathological cries studied. RF2 was also the highest among fullterm newborn cries, and its $\mathrm{A}_{\mathrm{SLP}}$ was the lowest among the newborn cries studied. We can infer from this that a reduced $\mathrm{A}_{\mathrm{SLP}}$ can be explained by the relative slowness of tongue movement, which is induced by the shortness of the transition and the long RF2 transition duration $\left(\mathrm{A}_{\mathrm{TRP}}\right)$ (Table 4). However, in this case, we noted a decrease in $\mathrm{A}_{\mathrm{TRP}}$, along with an increase in $\left(\mathrm{P}_{\mathrm{TUP}}\right)$ and $\left(\mathrm{A}_{\mathrm{TUP}}\right)$ for $\mathrm{RF}$, compared to the values of these parameters in healthy full-term newborns.

In another congenital malformation, Gastroschisis $(\mathrm{P})$, the average RF2 slopes $\left(\mathrm{A}_{\mathrm{SLP}}\right)$ are lower for newborn cries, which contain a high percentage of RF tuning $\left(\mathrm{P}_{\mathrm{TUP}}\right)$ and a long duration ( $\left.\mathrm{A}_{\mathrm{TUP}}\right)$ of RF1 tuning. In the case of the neurological disease IUGR-microcephaly $(\mathrm{P})$, highest medians of $\mathrm{A}_{\mathrm{F} 0}$ and $\mathrm{A}_{\mathrm{SLP}}$ were observed and also a high $\mathrm{P}_{\mathrm{TUP}}$ median and a low $A_{\text {TUP }}$ median for RF1. A long transition duration $\left(A_{T R P}\right)$ was also noted for RF1. This behavior is possibly the result of very rapid changes in the configuration of the vocal tract [28]. In the other neurological diseases, in IUGR_asphyxia (P), for example, high $A_{R F 1}, A_{R F 2}$, 
and $A_{\text {ratio }}$ values and a slow $A_{S L P}$ and long $A_{\text {TRP }}$ were observed. Asphyxia cries are characterized by a high $A_{F 0}$ and $A_{\text {ratio }}$, a low $A_{S L P}$ and high $A_{T R P}$ for RF2, and a high $A_{T R P}$ for RF1. In the heart defect diseases, the cries of newborns with Vena cava thrombosis (t) are characterized by a high $\mathrm{A}_{\mathrm{F} 0}$ and the lowest $\mathrm{A}_{\mathrm{RF} 1}$ and $\mathrm{A}_{\mathrm{RF} 2}$, and an $\mathrm{A}_{\text {ratio }}$ with a high ( $\left.\mathrm{A}_{\mathrm{SLP}}\right)$ and a high $\left(\mathrm{A}_{\mathrm{TRP}}\right)$ for RF1 and RF2. Tetralogy of Fallot $(\mathrm{P})$ cries contain the highest percentage of $\mathrm{RF} 1$ tuning $\left(\mathrm{AP}_{\mathrm{TUP}}\right)$ and a shorter $\mathrm{RF} 1$ and $\mathrm{RF} 2$ transition duration $\left(\mathrm{A}_{\mathrm{TRP}}\right)$. In this case, $\mathrm{A}_{\text {ratio }}$ is high with a low A ALP.

However, in the infectious diseases category, Meningitis ( $t$ ) and Peritonitis ( $t$ ), $A_{R F 1}$ and $A_{\text {ratio }}$ are lower. In Meningitis ( $\mathrm{t}$ ) cries, the $\mathrm{A}_{\mathrm{SLP}}$ and $\mathrm{A}_{\mathrm{TRP}}$ for both RF2 and RF1 are lower with a high $\mathrm{P}_{\text {TUP }}$ and $\mathrm{A}_{\mathrm{TUP}}$ for RF1. Unlike Meningitis ( $\mathrm{t}$ ), Peritonitis ( $\mathrm{t}$ ) cries are characterized by a low $\mathrm{A}_{\mathrm{RF} 2}$ and a high $\mathrm{A}_{\mathrm{TRP}}$ for RF1. In the respiratory disease category, $\mathrm{A}_{\mathrm{SLP}}$ is lower in RDS cries, and $\mathrm{P}_{\mathrm{TUP}}$ for $\mathrm{RF} 1$ and $\mathrm{A}_{\mathrm{TRP}}$ for $\mathrm{RF} 2$ are high.

We can surmise from the results of this study that there are three tuning patterns between the RFs and F0 in newborn cries. The first pattern is made up of a high percentage of long tuning duration times with short transition duration times, as in the case of Lingual frenum $(\mathrm{t})$ and Meningitis ( $\mathrm{t}$ ). In the second pattern, we find a high percentage of short tuning duration times with long transition duration times, as in IUGR-microcephaly. In the third pattern, the tuning percentage is low, but with a long duration time and long transition duration time, as for RF2 in healthy full-term newborns.

We note from our results that a decrease in RF1 and RF2 becomes more apparent in healthy newborns with increasing gestational age, which seems more relevant than the age at recording in this case.

To further investigate the influence of gestational age (full-term, preterm) on the characteristics measured, we performed an ANOVA variance analysis for healthy and 
pathological cries for each characteristic, to determine whether or not they change with gestational age. Our results, shown in Table 6, indicate significant statistical differences in all the assessed characteristics between healthy premature cries and healthy full-term cries. Only for the average transition duration of RF2 $\left(\mathrm{A}_{\mathrm{TRP}}\right)$ was no significant difference found based on gestational age. In the case of pathological cries, significant statistical differences $(\mathrm{F}=11.304, \mathrm{P}<0.05)$ between the average $\mathrm{RF} 2\left(\mathrm{~A}_{\mathrm{RF} 2}\right)$ of premature pathological cries and fullterm pathological cries was noted. For the remaining characteristics, no significant statistical differences were found based on gestational age. We have determined, therefore, that all the characteristics assessed, except for the transition duration of RF2, depend on gestational age in healthy cries. In pathological cries, with the exception of the average RF2, the assessed characteristics do not depend on gestational age, but rather on the pathology itself.

\section{Conclusion}

In this paper, a new automated method for newborn cry analysis is presented. This measurement method allows us to associate the most relevant characteristics with pathologies of interest, and also to extend the method to other pathologies.

The goal of this study has been to examine the possibility of classifying pathological and healthy cries on the basis of their acoustic attributes. We focused our investigation on the distribution of RFs and F0 in the cries of newborns 1 day to 1 month old. To identify the early relationship between these two frequencies, the tuning between the RFs and F0, and the transition duration were evaluated. Variation patterns of the RF1:RF2 ratio and the RF2 slope were also examined, based on the healthy and pathological cries studied.

The calculation of percentile values for each assessed characteristic provides details about its evolution in healthy and pathological cries. The distribution of these acoustic variables could be used to develop a quantitative metric to differentiate pathological cries from healthy ones. 
We conclude from our results that, even though laryngeal phonation and vocal tract-based articulation are independently controlled systems in newborns, these two systems interact according to the status of the newborn. Also, we infer that the characteristics of cries in the newborns we studied who were suffering from pathologies do not vary with gestational age, but rather mostly according to the pathology itself, which alters vocal folds and vocal tract resonance.

The results of this study suggest that the acoustic measures that we studied $\left(\mathrm{A}_{\mathrm{F} 0}, \mathrm{~A}_{\mathrm{RF} 1}, \mathrm{P}_{\mathrm{TUP}}\right.$, $\mathrm{A}_{\mathrm{TUP}}, \mathrm{A}_{\mathrm{TRP}}, \mathrm{A}_{\mathrm{SLP}}, \mathrm{A}_{\text {ratio }}$ ) all show significant differences among diseases. The automated approach presented in this paper for assessing these characteristics can be successfully used to distinguish pathological cries from healthy cries.

\section{ACKNOWLEDGMENTS}

This work is supported by the Bill \& Melinda Gates Foundation through the Grand Challenges Explorations Initiative. Special thanks to Dr. Barrington and members of the Neonatology group at Saint-Justine Hospital in Montreal (QC) for helping us to collect samples for the Infant Cry Database.

\section{references}

1. Michelson, k., H. Todd de Barra and O. Michelson. "Sound Spectrographic cry analysis and mothers perception of their infant's crying" In: Focus on nonverbal communication research, editors. Finley R. Lewis. New York: Nova Science Publishers, 2007; 31-64.

2. Wasz-Hockert, O. , K. Michelsson, J. Lind. "Twenty-five years of scandinavian cry research". In Infant Crying, edited by Lester, B. M. and C. F. Z. Boukydis, Springer US, 1985; 83-104.

3. Michelson K., K. Eklund, P. Leppanen, H. Lyytinen. Cry characteristics of 172 healthy 1- to 7-day-old infants. Folia Phoniatrica et Logopaedica 2002; 54: 190-200.

4. Lester, B. M., et L. L. LaGasse. "Crying ". In Encyclopedia of Infant and Early Childhood Development, editors, Haith, Marshall M., et Janette B. Benson, 2008; 332-343. San Diego: Academic Press. < http://www.sciencedirect.com/science/article/pii/B9780123708779000451 >.

5. LaGasse, L. L., A. R. Neal and B. M. Lester. Assessment of the infant cry: Acoustic cry analysis and parental perception. Mental Retardation and Developmental Disabilities, 2005; 11: 83-93.

6. Soltis, J., The signal functions of early infant crying. Behavioral and Brain Sciences, 2004; 27: 443-490.

7. Buder E. H., L. B. Chorna, D. K. Oller and R. B. Robinson. Vibratory regime classification of infant phonation. Journal of Voice, 2008; 22: 553-564. 
8. Cecchini, M., C. Lai and V. Langher. Dysphonic newborn cries allow prediction of their perceived meaning. Infant Behavior \& Development, 2010; 33: 314-320.

9. Kim Y., G. Weismer, R. D. Kent and J. R. Duffy. Statistical models of f2 slope in relation to dysarthria severity. Folia Phoniatr Logop , 2009; 61: 329-335.

10. Wermk, K., W. Mende, A. Kempf, C. Manfredi, P. Bruscaglioni and A. Stellzig-Eisenhauer. Interaction patterns between melodies and resonance frequencies in infants' pre-speech utterances. In Proceedings of the 4th International Workshop. Models and Analysis of Vocal Emissions for Biomedical Applications, 2005; 187-190.

11. Kim Y., R. D. Kent and G. Weismer. An acoustic study of the relationships among dysarthria-type neurological diseases and dysarthria severity. Journal of Speech Language and Hearing Research, 2011; 54: 417-429.

12. Kheddache, Y., C. Tadj. Frequential characterization of healthy and pathologic newborn cries. American Journal of Biomedical Engineering, 2013; 3: 182-193.

13. Kheddache, Y., C. Tadj .Characterization of Pathological Cries of Newborns based on Fundamental Frequency Estimation. Engineering, 2013; 5: 272-276.

14. Manfredi, C., W. Mende, P. Bruscaglioni and K. Wermke. Resonance development and formant tuning phenomena in infant's crying. In: Proc. $3^{\text {rd }}$ Int. Workshop MAVEBA, 2003; 35-38.

15. Poissant, S. F., K. A. Petersa and M. P. Robb. Acoustic and perceptual appraisal of speech production in pediatric cochlear implant users. International Journal of Pediatric Otorhinolaryngology , 2006; 70: 1195-1203.

16. Seifert E., M. Oswald, U. Bruns, M. Vischer, M. Komis and R. Haeusler. Change of voice and articulation in children with cochlear implants. International Journal of Pediatric Otorhinolaryngology, 2002; 66: 115-123.

17. Kasuya H., S. Ogawa, K. Mashima and S. Ebihara. Normalised noise measure to evaluate the pathological voice. Journal of the Acoustical Society of America, 1986; 80: 1329-1334.

18. Manfredi C., L. Bocchi, S. Orlandi, L. Spaccaterra and G. P. Donzelli. High-resolution cry analysis in preterm newborn infants. Medical Engineering \& Physics, 2009; 31: 528-532.

19. Fort, A., C. Manfridi. Acoustic analysis of newborn infant cry signals. Medical Engineering \& Physics, 1998; 20: 432-442.

20. Kheddache, Y., C. Tadj. Acoustic measures of the cry characteristics of healthy newborns and newborns with pathologies. Journal of Biomedical Science \& Engineering, 2013; 6: 796-804.

21. Sundberg J., Filipa, M., B. La, B. P. Gill. Formant Tuning Strategies in Professional Male Opera Singers. Journal of Voice,2013; 27: 278-288.

22. Varallyay G., A. Illényi, Z. Benyo, Z. Farkas and G. Katona. An attempt to detect hearing disorders by acoustic features of the infant cry. In Proceedings of the Forum Acusticum Congress, Budapest, 2005, 1-6.

23. Verduzco-Mendoza A., E. Arch-Tirado, C. A. Garcia, J. L. Ibarra. "Qualitative and quantitative crying analysis of newborn babies delivered under high risk gestation". In Multimodal Signals: Cognitive and Algorithmic Issues, editors : de Esposito, Anna, Amir Hussain, Maria Marinaro and Raffaele Martone. Springer Berlin Heidelberg, 2009; 5398: 320-327.

24. Michael C., P. Robb, A. T. Cacace. Estimation of formant frequencies in the infant cry. International Journal of Pediatric Otorhinoiaryngology, 1995; 32:57-67. 
25. Markel J. D.,The SIFT Algorithm for Fundamental Frequency Estimation. IEEE Trans. Audio Electroacoustic, 1972; 20:367-377,.

26. Fort A., C. Manfredi. Acoustic analysis of newborn infant cry signals. Medical Engineering \& Physics; 1998, 20: $432-442$,

27. Manfredi C., V. Tocchioni, L. Bocchi. A robust tool for newborn infant cry analysis. Proceedings of the 28th IEEE, EMBS Annual International Conference, 2006, 509-512.

28. Kim Y., G. Weismer, R. D. Kent and J. R. Duffy. Statistical Models of F2 Slope in Relation to the Severity of Dysarthria. Folia Phoniatr Logop, 2009, 61: 329-335. 
Table 1. Pathologies Studied

\begin{tabular}{|c|c|c|c|}
\hline $\begin{array}{l}\text { Gestation } \\
\text { al age }\end{array}$ & Pathology & $\begin{array}{c}\text { Age at } \\
\text { recording } \\
\text { (days) }\end{array}$ & $\begin{array}{c}\text { Sample } \\
\text { size }\end{array}$ \\
\hline \multirow{6}{*}{$\begin{array}{l}\text { Full-term } \\
\text { newborn } \\
\text { (t) }\end{array}$} & Healthy & 1 to 3 & 1010 \\
\hline & $\begin{array}{l}\text { Vena cava } \\
\text { thrombosis }\end{array}$ & 2 to 3 & 77 \\
\hline & Meningitis & 14 to 15 & 115 \\
\hline & Peritonitis & 28 & 20 \\
\hline & Asphyxia & 4 to 28 & 190 \\
\hline & $\begin{array}{l}\text { Lingual } \\
\text { frenum }\end{array}$ & 1 to 2 & 141 \\
\hline \multirow{7}{*}{$\begin{array}{l}\text { Preterm } \\
\text { newborn } \\
\text { (P) }\end{array}$} & Healthy & 3 to 28 & 764 \\
\hline & $\begin{array}{l}\text { IUGR - } \\
\text { Microcephaly } \\
\text { (in utero } \\
\text { growth } \\
\text { retardation) }\end{array}$ & 1 & 78 \\
\hline & $\begin{array}{l}\text { Tetralogy of } \\
\text { Fallot }\end{array}$ & 17 & 53 \\
\hline & Gastroschisis & 6 to 20 & 134 \\
\hline & $\begin{array}{l}\text { IUGR - } \\
\text { Asphyxia }\end{array}$ & & \\
\hline & $\begin{array}{l}\text { (intra-uterine } \\
\text { growth } \\
\text { retardation) }\end{array}$ & 30 & 148 \\
\hline & $\begin{array}{l}\text { RDS } \\
\text { (respiratory } \\
\text { distress } \\
\text { syndrome) }\end{array}$ & 28 & 270 \\
\hline
\end{tabular}


Table 2. Cry Characteristics Measured

\begin{tabular}{ll}
\hline Characteristic & Definition \\
\hline $\begin{array}{l}\text { Fundamental } \\
\text { frequency }\left(\mathrm{F}_{0}\right)\end{array}$ & $\begin{array}{l}\text { Vibration frequency (in Hz) of the } \\
\text { vocal folds. }\end{array}$ \\
\hline Harmonics & Multiples of fundamental frequency \\
\hline $\begin{array}{l}\text { RF1, RF2 } \\
(\mathrm{Hz})\end{array}$ & $\begin{array}{l}\text { First and second vocal tract } \\
\text { resonance frequencies }\end{array}$ \\
\hline $\begin{array}{l}\text { RF1:RF2 } \\
\text { ratio }\end{array}$ & Derived using RF1 and RF2 \\
\hline $\begin{array}{l}\text { Tuning } \\
(\mathrm{TUP})\end{array}$ & $\begin{array}{l}\text { Blocks of 1024 samples during } \\
\text { which an RF remains close to the } \\
\text { harmonics of F0 (distance <100 Hz) }\end{array}$ \\
\hline $\begin{array}{l}\text { Tuning } \\
\text { duration (ms) }\end{array}$ & $\begin{array}{l}\text { The time between the start and end } \\
\text { of tuning }\end{array}$ \\
\hline $\begin{array}{l}\text { Transition } \\
\text { duration } \\
\text { (TRP) (ms) }\end{array}$ & $\begin{array}{l}\text { Duration between two subsequent } \\
\text { TUPs, or the time between the start } \\
\text { and end of transition }\end{array}$ \\
\hline $\begin{array}{l}\text { Transition extent } \\
\text { (Hz) }\end{array}$ & $\begin{array}{l}\text { Frequency change between the } \\
\text { transition start and end }\end{array}$ \\
\hline $\begin{array}{l}\text { RF2 slope } \\
(\text { Hz/ms) }\end{array}$ & $\begin{array}{l}\text { Derived using transition extent and } \\
\text { duration measures. }\end{array}$ \\
\hline
\end{tabular}


Table 3. Measured Characteristics of Cries

\begin{tabular}{|c|c|c|c|c|c|c|c|c|c|c|}
\hline \multirow[b]{2}{*}{ Pathology } & \multicolumn{2}{|c|}{$\mathrm{A}_{\mathrm{F} 0}(\mathrm{~Hz})$} & \multicolumn{2}{|c|}{$\mathrm{A}_{\mathrm{RF} 1}(\mathrm{~Hz})$} & \multicolumn{2}{|c|}{$\mathrm{A}_{\mathrm{RF} 2}(\mathrm{~Hz})$} & \multicolumn{2}{|r|}{$\mathrm{A}_{\text {ratio }}$} & \multicolumn{2}{|c|}{$\mathrm{A}_{\mathrm{slp}}(\mathrm{Hz} / \mathrm{ms})$} \\
\hline & Median & $\begin{array}{l}\text { Inter-quartile } \\
\text { range }\end{array}$ & Median & $\begin{array}{l}\text { Inter-quartile } \\
\text { range }\end{array}$ & Median & $\begin{array}{l}\text { Inter-quartile } \\
\text { range }\end{array}$ & Median & $\begin{array}{l}\text { Inter-quartile } \\
\text { range }\end{array}$ & Median & $\begin{array}{l}\text { Inter-quartile } \\
\text { range }\end{array}$ \\
\hline Healthy $(\mathrm{t})$ & 456 & 94 & 955 & 311 & 3024 & 559 & 0.31 & 0.11 & 9.5 & 7.43 \\
\hline Lingual frenum $(\mathrm{t})$ & 462 & 168 & 1569 & 609 & 3393 & 738 & 0.46 & 0.08 & 4.63 & 4.82 \\
\hline $\begin{array}{l}\text { Vena cava thrombosis } \\
\text { (t) }\end{array}$ & 501 & 128 & 754 & 456 & 2817 & 601 & 0.25 & 0.14 & 11.88 & 10.58 \\
\hline Asphyxia $(\mathrm{t})$ & 536 & 272 & 997 & 255 & 3002 & 635 & 0.35 & 0.1 & 6.98 & 7.06 \\
\hline Meningitis ( $\mathrm{t}$ ) & 415 & 79 & 867 & 118 & 3009 & 281 & 0.28 & 0.05 & 7.67 & 6.06 \\
\hline Peritonitis $(\mathrm{t})$ & 440 & 105 & 846 & 248 & 2885 & 632 & 0.28 & 0.06 & 9.41 & 8.8 \\
\hline Healthy $(\mathrm{P})$ & 417 & 89 & 1045 & 314 & 3447 & 641 & 0.3 & 0.09 & 9.05 & 8.52 \\
\hline Gastroschisis $(\mathrm{P})$ & 433 & 174 & 1009 & 414 & 3388 & 620 & 0.33 & 0.08 & 7.35 & 8.79 \\
\hline RDS (P) & 449 & 131 & 991 & 192 & 3347 & 616 & 0.31 & 0.06 & 7.7 & 8.01 \\
\hline IUGR_asphyxia (P) & 400 & 98 & 1411 & 269 & 3878 & 773 & 0.4 & 0.06 & 7.14 & 7.15 \\
\hline Tetralogy of Fallot (P) & 479 & 74 & 1180 & 79 & 3256 & 222 & 0.37 & 0.05 & 7.37 & 6.07 \\
\hline IUGR-microcephaly (P) & 587 & 156 & 1028 & 241 & 3300 & 482 & 0.3 & 0.1 & 12.85 & 10.32 \\
\hline
\end{tabular}


Table 4. Measured Characteristics of Cries

\begin{tabular}{|c|c|c|c|c|c|c|c|c|c|c|c|c|}
\hline \multirow[b]{2}{*}{ Pathology } & \multicolumn{2}{|c|}{$\mathrm{P}_{\mathrm{TUP}}$ for RF1 (\%) } & \multicolumn{2}{|c|}{$\mathrm{A}_{\mathrm{TUP}}$ for RF1 (ms) } & \multicolumn{2}{|c|}{$\mathrm{A}_{\mathrm{TRP}}$ for RF1 (ms) } & \multicolumn{2}{|c|}{$\mathrm{P}_{\mathrm{TUP}}$ for RF2 (\%) } & \multicolumn{2}{|c|}{$\mathrm{A}_{\mathrm{TUP}}$ for RF2 (ms) } & \multicolumn{2}{|c|}{$\mathrm{A}_{\mathrm{TRP}}$ for RF2 (ms) } \\
\hline & Median & $\begin{array}{l}\text { Inter-quartile } \\
\text { range }\end{array}$ & Median & $\begin{array}{l}\text { Inter-quartile } \\
\text { range }\end{array}$ & Median & $\begin{array}{l}\text { Inter-quartile } \\
\text { range }\end{array}$ & Median & $\begin{array}{l}\text { Inter-quartile } \\
\text { range }\end{array}$ & Median & $\begin{array}{l}\text { Inter-quartile } \\
\text { range }\end{array}$ & Median & $\begin{array}{l}\text { Inter-quartile } \\
\text { range }\end{array}$ \\
\hline Healthy (t) & 4.2 & 1.6 & 22 & 11.2 & 116.1 & 57 & 3.7 & 1.3 & 31.6 & 8.6 & 96.5 & 39.1 \\
\hline Lingual frenum (t) & 5 & 1.6 & 34.2 & 9.8 & 87.5 & 42.3 & 2.5 & 1.8 & 24.4 & 11.3 & 146.3 & 109 \\
\hline $\begin{array}{l}\text { Vena cava } \\
\text { thrombosis(t) }\end{array}$ & 3.1 & 2.5 & 19.8 & 15.9 & 160 & 85.1 & 3.4 & 2 & 22.3 & 9.3 & 112.2 & 56.9 \\
\hline Asphyxia (t) & 4 & 2 & 25.4 & 9.9 & 127.7 & 69.5 & 2.5 & 1.5 & 25.4 & 10.3 & 127.7 & 69.4 \\
\hline Meningitis (t) & 5.2 & 2 & 32.6 & 15.3 & 95.5 & 53.8 & 4.6 & 1.3 & 29.3 & 10.4 & 78 & 25 \\
\hline Peritonitis (t) & 4.6 & 2.3 & 35 & 11.7 & 140.5 & 64.3 & 4.2 & 1.8 & 36.3 & 13.6 & 92.8 & 39.5 \\
\hline Healthy $(\mathrm{P})$ & 4.5 & 1.8 & 27.2 & 12.7 & 116.1 & 64 & 3.3 & 1.5 & 25.4 & 9 & 110.7 & 58.7 \\
\hline Gastroschisis $(\mathrm{P})$ & 5.2 & 2.1 & 33.3 & 13 & 108 & 64.7 & 3 & 1.5 & 25.2 & 8.2 & 133.8 & 79 \\
\hline RDS (P) & 4.7 & 2.3 & 35.1 & 16.4 & 101.5 & 47.9 & 2.5 & 1.7 & 23.6 & 10.8 & 123.2 & 70.6 \\
\hline IUGR_asphyxia (P) & 3.3 & 1.8 & 25.9 & 7.6 & 90.5 & 50.1 & 3.4 & 1.4 & 33 & 10.5 & 140.4 & 104.3 \\
\hline $\begin{array}{l}\text { Tetralogy of Fallot } \\
\text { (P) }\end{array}$ & 5.5 & 2.3 & 26.5 & 11.7 & 84 & 47.3 & 3.6 & 1.7 & 26.7 & 9.7 & 94.6 & 55.9 \\
\hline $\begin{array}{l}\text { IUGRicrocephaly } \\
\text { (P) }\end{array}$ & 5 & 1.4 & 23.2 & 5.64 & 135 & 60 & 3.1 & 1.4 & 23.5 & 4 & 101.9 & 44.9 \\
\hline
\end{tabular}


Table 5. Cry Characteristics Associated with the Pathologies Studied

\begin{tabular}{|c|c|}
\hline Pathologies & Cry characteristics \\
\hline Lingual frenum(t) & $\uparrow R F 1, \uparrow R F 1$ tuning,$\downarrow R F 1$ transition, $\uparrow R F 2, \downarrow R F 2$ tuning,$\uparrow R F 2$ transition, $\uparrow$ RF1:RF2 ratio, $\downarrow$ slope $R F 2$ \\
\hline Vena cava thrombosis $(\mathrm{t})$ & $\uparrow F 0, \downarrow R F 1, \downarrow R F 1$ tuning,$\uparrow R F 1$ transition, $\downarrow R F 2, \downarrow R F 2$ tuning, $\uparrow R F 2$ transition, $\downarrow R F 1: R F 2$ ratio, $\uparrow$ slope $R F 2$ \\
\hline Asphyxia (t) & $\uparrow F 0, \uparrow R F 1$ transition, $\uparrow \mathrm{RF} 2$ transition, $\uparrow \mathrm{RF} 1: \mathrm{RF} 2$ ratio, $\downarrow$ slope $\mathrm{RF} 2$ \\
\hline Meningitis (t) & $\downarrow R F 1, \uparrow R F 1$ tuning, $\downarrow R F 1$ transition, $\uparrow R F 2$ tuning, $\downarrow R F 2$ transition, $\downarrow R F 1: R F 2$ ratio, $\downarrow$ slope $R F 2$ \\
\hline Peritonitis $(\mathrm{t})$ & $\downarrow R F 1, \downarrow R F 2, \uparrow R F 1$ tuning, $\uparrow R F 1$ transition, $\uparrow R F 2$ tuning, $\downarrow R F 2$ transition, $\downarrow R F 1$ :RF2 ratio \\
\hline Healthy $(\mathrm{P})$ & $\uparrow \mathrm{RF} 1, \uparrow \mathrm{RF} 2, \downarrow \mathrm{RF} 2$ tuning, $\uparrow \mathrm{RF} 2$ transition \\
\hline Gastroschisis $(\mathrm{P})$ & $\downarrow R F 1, \uparrow R F 1$ tuning, $\downarrow R F 1: R F 2$ ratio, $\uparrow R F 2$ transition, $\downarrow$ slope $R F 2$ \\
\hline $\mathrm{RDS}(\mathrm{P})$ & $\downarrow R F 1, \uparrow R F 2, \uparrow R F 1$ tuning, $\downarrow R F 2$ tuning, $\uparrow R F 2$ transition, $\downarrow$ slope $R F 2$ \\
\hline IUGR_asphyxia(P) & $\uparrow R F 1, \downarrow R F 1$ tuning, $\downarrow R F 1$ transition, $\uparrow R F 2, \uparrow R F 2$ tuning, $\uparrow R F 2$ transition, $\uparrow R F 1$ :RF2 ratio, $\downarrow$ slope $R F 2$ \\
\hline Tetralogy of Fallot $(\mathrm{P})$ & $\uparrow R F 1$ tuning, $\downarrow R F 1$ transition, $\uparrow \mathrm{RF} 2$ tuning, $\downarrow R F 2$ transition, $\uparrow$ RF1:RF2 ratio, $\downarrow$ slope $R F 2$ \\
\hline IUGR-microcephaly (P) & $\uparrow F 0, \uparrow R F 2, \uparrow R F 1$ tuning, $\uparrow R F 1$ transition, $\downarrow R F 2$ tuning, $\uparrow$ slope $R F 2$ \\
\hline
\end{tabular}


Table 6. Analysis of Variance (ANOVA) based on Gestational Age

\begin{tabular}{ccccc}
\hline \multirow{2}{*}{ Characteristic } & \multicolumn{2}{c}{ Healthy } & \multicolumn{2}{c}{ Pathological } \\
\cline { 2 - 5 } & F & $\boldsymbol{p}$ & $\mathbf{F}$ & $\boldsymbol{p}$ \\
\hline $\mathrm{A}_{\mathrm{F} 0}$ & $\mathbf{2 1 8 . 0 6 4}$ & $\mathbf{0 . 0 0 0}$ & 0.052 & 0.824 \\
\hline $\mathrm{A}_{\mathrm{RF} 1}$ & $\mathbf{3 1 1 . 0 6 1}$ & $\mathbf{0 . 0 0 0}$ & 0.683 & 0.428 \\
\hline $\mathrm{A}_{\mathrm{RF} 2}$ & $\mathbf{6 3 . 7 6 2}$ & $\mathbf{0 . 0 0 0}$ & $\mathbf{1 1 . 3 0 4}$ & $\mathbf{0 . 0 0 7}$ \\
\hline $\mathrm{A}_{\text {ratio }}$ & $\mathbf{2 2 5 . 7 7 0}$ & $\mathbf{0 . 0 0 0}$ & 0.143 & 0.713 \\
\hline $\mathrm{A}_{\mathrm{SLP}}$ & $\mathbf{4 3 . 5 7 0}$ & $\mathbf{0 . 0 0 0}$ & 0.036 & 0.853 \\
\hline $\mathrm{P}_{\mathrm{TUP} \text { for }} \mathrm{RF} 1$ & $\mathbf{5 8 . 3 3 2}$ & $\mathbf{0 . 0 0 0}$ & 0.623 & 0.448 \\
\hline $\mathrm{A}_{\mathrm{TUP} \text { for }} \mathrm{RF} 1$ & $\mathbf{2 5 . 1 1 9}$ & $\mathbf{0 . 0 0 0}$ & 0.012 & 0.913 \\
\hline $\mathrm{A}_{\mathrm{TRP} \text { for }} \mathrm{RF} 1$ & $\mathbf{4 4 . 8 9 0}$ & $\mathbf{0 . 0 0 0}$ & 1.304 & 0.280 \\
\hline $\mathrm{P}_{\mathrm{TUP} \text { for }} \mathrm{RF} 2$ & $\mathbf{3 2 2 . 1 7 5}$ & $\mathbf{0 . 0 0 0}$ & 0.743 & 0.409 \\
\hline $\mathrm{A}_{\mathrm{TUP}} \mathrm{RF} 2$ & $\mathbf{5 3 6 . 5 6 5}$ & $\mathbf{0 . 0 0 0}$ & 1.304 & 0.280 \\
\hline $\mathrm{A}_{\mathrm{TRP} \text { for }} \mathrm{RF} 2$ & 0.780 & 0.377 & 0.458 & 0.514 \\
\hline
\end{tabular}




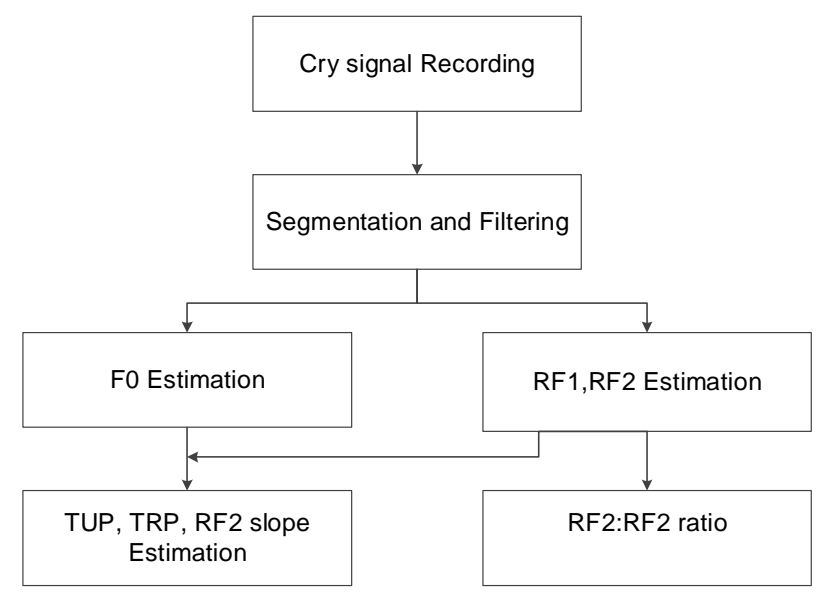

Figure 1. Methodology. ("Signal”; "Filtering", "RF1, RF2", "Slope", "Ratio") 


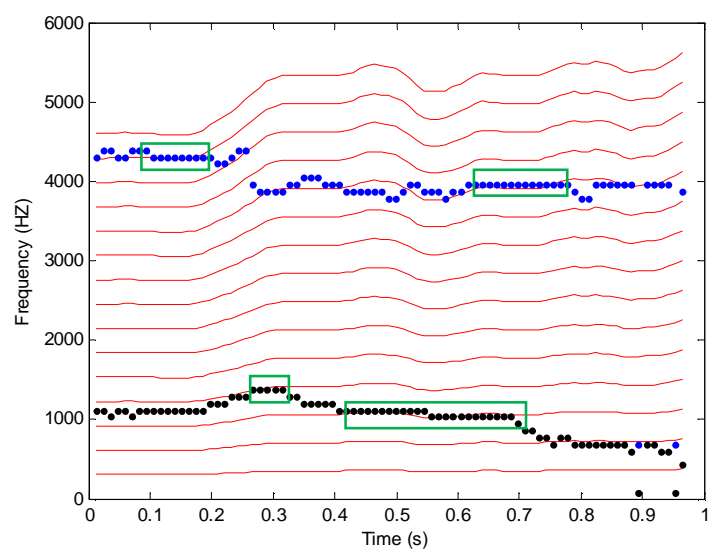

a) Healthy preterm infant

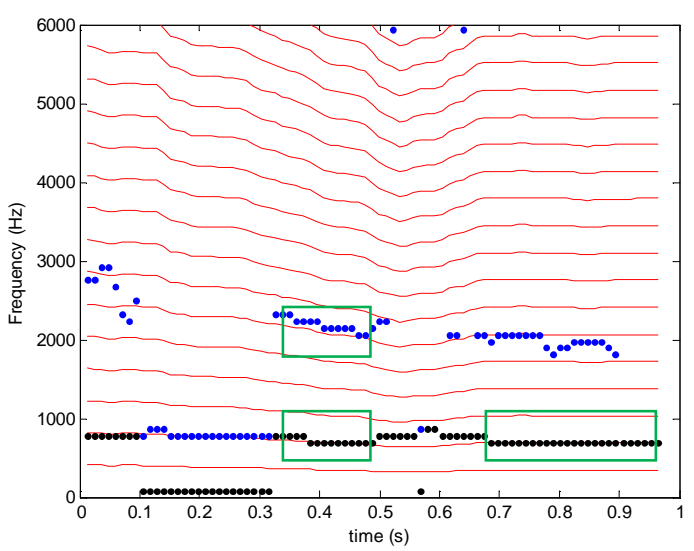

c) Gastroschisis

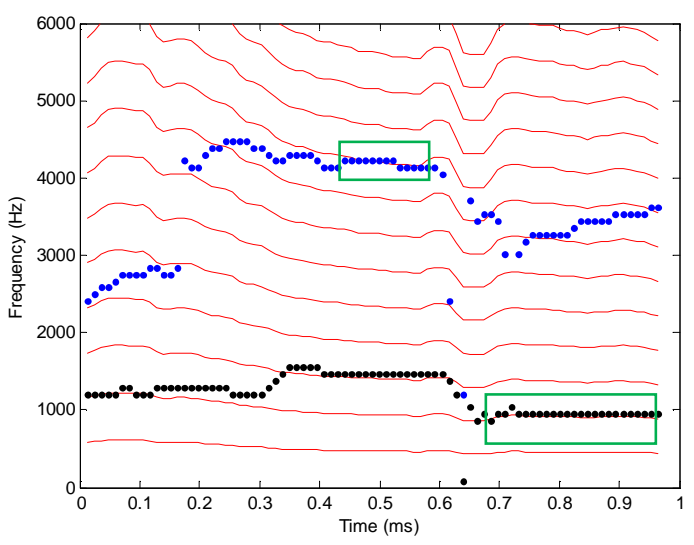

e) IUGR-microcephaly (P)

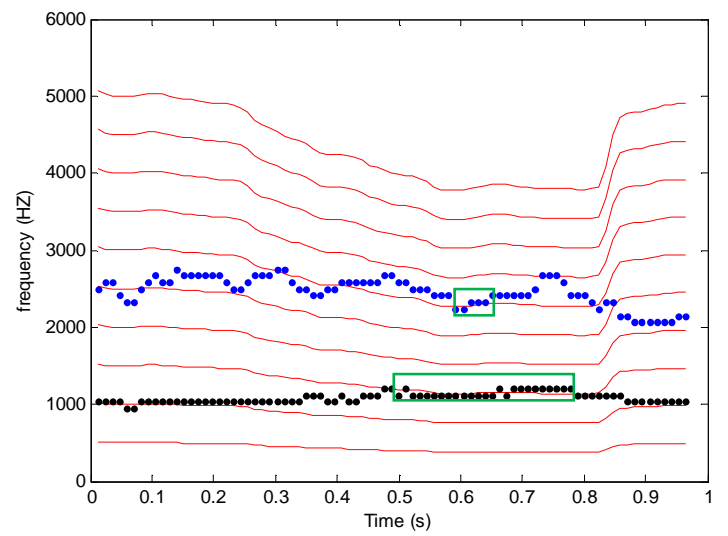

b) Healthy full-term infant

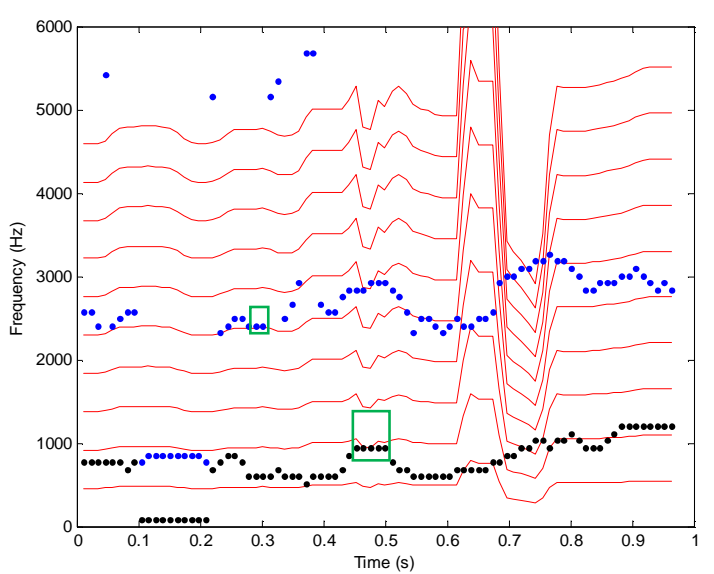

d) Vena cava thrombosis

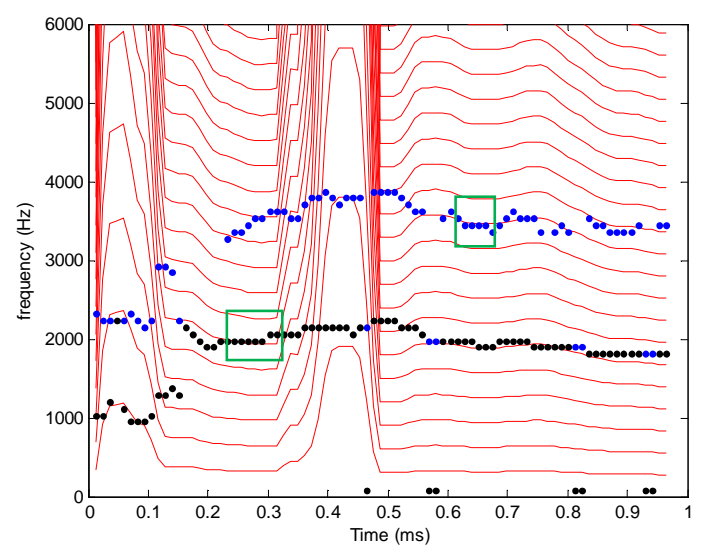

f) Lingual frenum (t)

Figure 2. Fundamental frequencies and their harmonics (red lines), resonance frequencies: RF1 (black dots) and RF2 (blue dots), tuning between the RFs and F0 harmonics (green rectangles) 


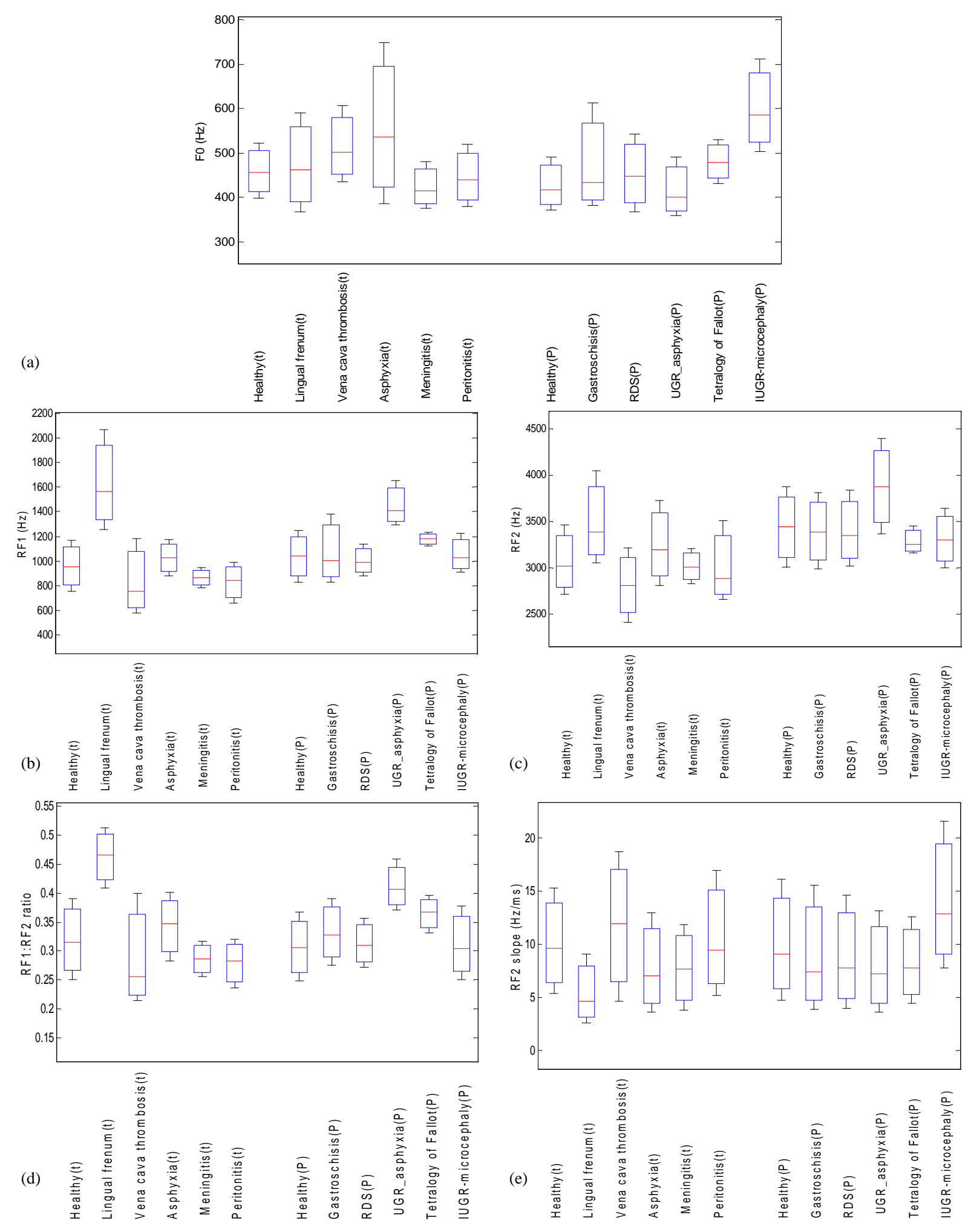

Figure 3. Box-and-whiskers plots for the averages of: (a) F0, (b) RF1, (c) RF2,

(d) the RF1:RF2 ratio, (e) the RF2 slope, by pathology and gestational age 

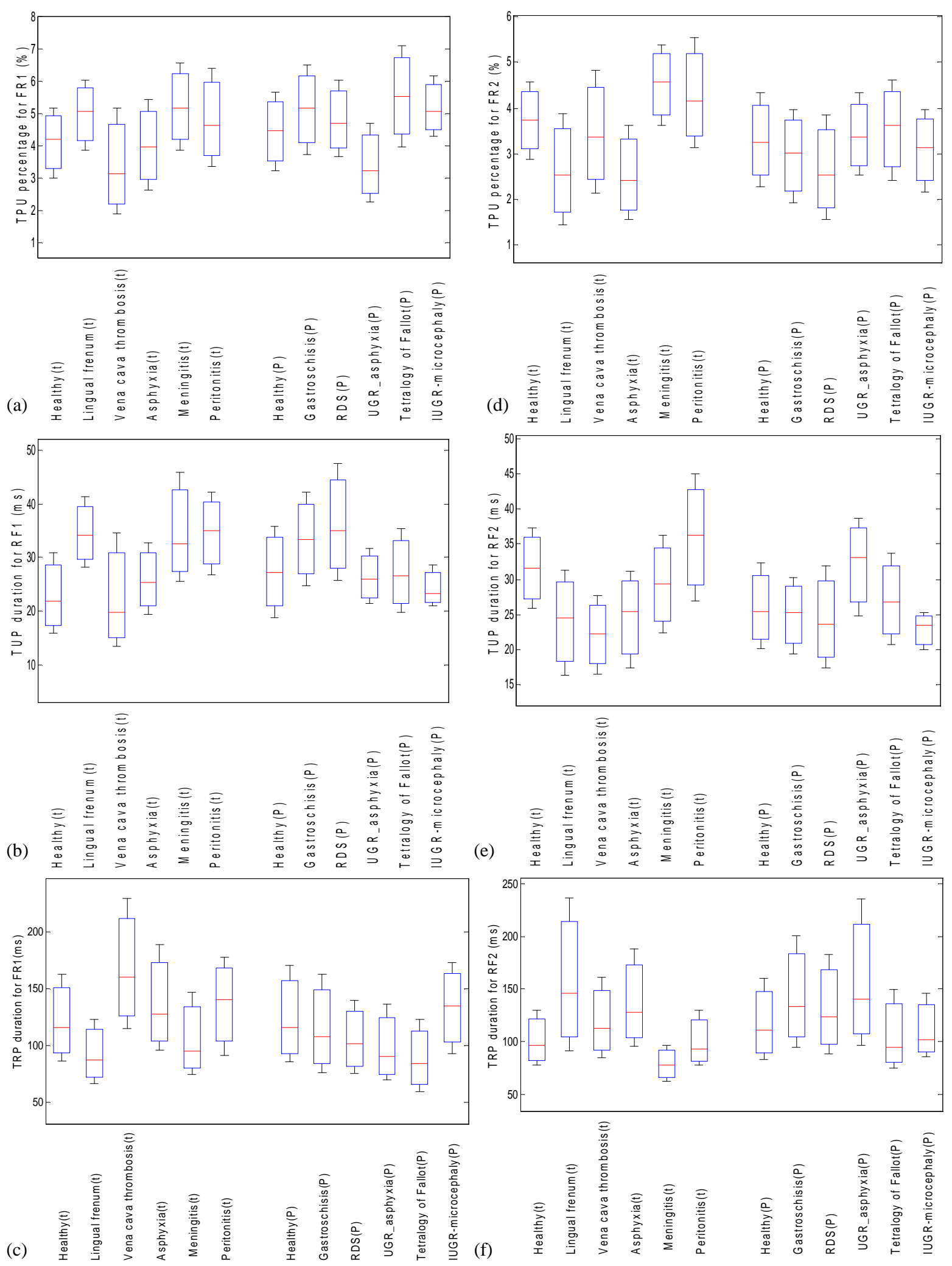

Figure 4. box-and-whiskers plots for the average of : (a) $P_{T U P}$ for RF1, (b) $A_{T R P}$ for RF1, (c) $A_{T R P}$ for RF1 (d) $\mathrm{P}_{\mathrm{TUP}}$ for RF2, (e) $\mathrm{A}_{\mathrm{TRP}}$ for RF2, (f) $\mathrm{A}_{\mathrm{TRP}}$ for RF2, by pathology and gestational age. 